\title{
Space Occupancy Method for Estimation of PCUs of Vehicles at Different Speed and Flow Ranges on Urban Road
}

\section{S.Srikanth}

1. Assistant Professor, School of civil engineering, Reva University, Bangalore-560064, India; e-mail: srikanthsreddy@ reva.edu.in

\section{Publication Info}

Article history :

Received : $31^{\text {st }}$ July, 2019

Accepted : $30^{\text {th }}$ Nov., 2019

DOI : 10.18090/samriddhi.v11i02.1

Keywords: PCU, Space-Occupancy,

Urban roads, Density

*Corresponding author :

S Srikanth

e-mail : srikanthsreddy@ reva.edu.in

\begin{abstract}
The problem of quantification of volume under heterogeneous traffic has been addressed by converting the different types of vehicles into equivalent passenger cars and expressing the volume or capacity of roads in terms of PCU per hour. The traffic movement under heterogeneous traffic condition differs, however, significantly from that of homogeneous traffic in respect of the pattern of occupancy of road space by vehicles. Video graphic technique was used for the traffic flow data collection. A Traffic Enumeration Software was used for extracting speed, flow and headway data. Space occupancy method was used for PCU determination where in the space headway of each vehicle was also taken into consideration along with the projected area of the vehicle. Dynamic PCU values of different vehicles were found out corresponding to both speed and flow ranges. Reliability of dynamic PCU values of different vehicles is also determined by using density.
\end{abstract}

\section{INTRODUCTION}

$\mathrm{T}_{\mathrm{H}}$ he primary function of urban roads is to convey traffic between centers of population/ activity, or within the urban area. A large number of vehicles will be using these urban roads daily and it should be made sure that the facility is used optimally, without exceeding the capacity at any point of time. Vehicle capacity is defined as the maximum number of vehicles that can pass a given point during a specified period, usually taken as one hour for majority of the cases, under prevailing roadway, traffic and control conditions. Capacity analysis is a set of procedures for estimating the traffic carrying ability of facilities over a range of defined operational condition. It examines segments or points of facility under uniform traffic, roadway and control conditions. These conditions determine capacity; therefore segments with different prevailing conditions will have different capacities.

Different vehicle types occupy different spaces on the road, move at different speeds, and start at different accelerations. Furthermore, the behavior of drivers of the different types of vehicles may also vary considerably. This poses a problem for designing roads, intersections, and traffic signals. A uniform measure of vehicles is thus necessary to estimate traffic volume and capacity of roads under mixed traffic flow. This is rather difficult to achieve unless the different vehicle types are stated in terms of a common standard vehicle unit, namely Passenger Car Unit (PCU). There exists large variation in the equivalency factors being adopted in different parts of the world since it varies from location to location. 
The objective of this study is to determine the equivalency factor for each category of vehicle at different speed and flow ranges on urban roads using space occupancy method. The estimated dynamic PCU values can be used for further studies like level of service conducted in the study location.

\section{LITERATURE REVIEW}

For estimating PCUs, area occupancy proposed by Mallikarjuna and Rao (2006) is used instead of density as it does not represent the mixed traffic characteristics appropriately. Swamy et al. (2016) also estimated PCU based on influence area which is found to be more logical when estimated at different flow conditions on expressways.

Paul and Sarkar (2013) have done a case study on urban arterial roads of Delhi, where PCUs of different vehicle types were estimated by considering speed and influence area as parameters. Authors modified the dynamic PCU method.

Preethi and Ashalata (2016) estimated dynamic PCU using area occupancy concept at signalized intersection. The study facilitated easy and quick estimation of dynamic PCU values, based on mathematical models incorporating the effect of traffic composition and saturation flow.

Mishra et al. (2017) developed a novel areaoccupancy based methodology for estimation of PCU values for different category of vehicles under heterogeneous traffic conditions on multilane urban roads for a wide range of traffic flow levels. Authors found that the PCU values suggested by IRC and dynamic PCU concept using speed-area ratio, underestimates and overestimates the flows, respectively at different traffic volumes. However, the values obtained using area occupancy concept is found to be consistent with the traffic flow in cars-only traffic situation at different flow conditions.
Kumar et al. (2017) focused on PCU estimation using area occupancy as measure of base for different vehicle classes on multilane urban roads under mixed traffic conditions. Using TRRLs definition of PCU, they replaced stream speed with area occupancy at different $\mathrm{V} / \mathrm{C}$ ratio.

Srikanth and Mehar (2017) by considering factors influencing PCU and available methodologies, modification to the dynamic PCU method has been proposed. Unlike dynamic PCU method, this method includes time headway factor for PCU estimation. The PCU value of a subjected vehicle type is estimated as the product of speed factor, headway factor and area factor.

Kumar et al (2018) proposed new methodology for PCU estimation using area occupancy under non-lane-based heterogeneous traffic conditions on multilane urban roads. The results show that an increase in the number of lanes or in carriageway width has a significant increasing effect on PCU values of vehicle categories. Authors validated PCU values using a test section of an eight-lane divided road having similar roadway and traffic conditions. The error is well within acceptable limits $(0.3-3 \%)$ at the capacity-flow level.

Pooja et al. (2018) determined the PCUs for each type of vehicle by considering the speed and effective area of subject and neighboring vehicles. Pooja et al. (2019) reviewed the various methods used for estimating PCUs for different types under homogeneous and heterogeneous traffic conditions and the drawbacks of the existing methods are identified.

\section{STUDY AREA AND DATA COLLECTION}

The study section is unaffected by major intersections to get uninterrupted traffic flow conditions and also free from the effect of bus stops, bus stands, fueling stations etc. TRUNK 
road, Ongole city selected as study area. TRUNK road is the mid-block section, a dual carriageway, thus the lanes running in the two directions are considered separately as two roads. The details of study section are given in Table-1.

Table-1: Details of study sections

\begin{tabular}{|c|c|c|c|c|c|c|c|}
\hline $\begin{array}{c}\text { Study } \\
\text { section }\end{array}$ & $\begin{array}{c}\text { Carriage } \\
\text { way } \\
\text { width (m) }\end{array}$ & $\begin{array}{c}\text { Distance of section } \\
\text { from both } \\
\text { intersections (m) }\end{array}$ & $\begin{array}{c}\text { Distance } \\
\text { from bus } \\
\text { stop (m) }\end{array}$ & $\begin{array}{c}\text { Distance } \\
\text { from bus } \\
\text { stand (m) }\end{array}$ & $\begin{array}{c}\text { Presence of } \\
\text { shoulder or } \\
\text { sidewalk }\end{array}$ & $\begin{array}{c}\text { Type of } \\
\text { farking }\end{array}$ \\
\hline $\begin{array}{c}\text { TRUNK } \\
\text { road } \\
\text { (direction1) }\end{array}$ & 7.33 & 110.73 & 247.3 & No bus stop & $\begin{array}{c}\text { No bus } \\
\text { stand }\end{array}$ & $\begin{array}{c}\text { Sidewalk } \\
\text { present }\end{array}$ & $\begin{array}{c}\text { On-street } \\
\text { parking }\end{array}$ \\
\hline $\begin{array}{c}\text { TRUNK } \\
\text { road } \\
\text { (direction 2) }\end{array}$ & 6.35 & 247.3 & 110.73 & No bus stop & $\begin{array}{c}\text { No bus } \\
\text { stand }\end{array}$ & $\begin{array}{c}\text { Sidewalk } \\
\text { present }\end{array}$ & $\begin{array}{c}\text { No } \\
\text { parking }\end{array}$ \\
\hline
\end{tabular}

A longitudinal trap length was marked on the selected section of the road with a tape, so that the exit and entry of the section was clearly visible. The video camera was set up at suitable locations so that the exit and entry of the marked sections selected were clearly visible. In order to not influence the driver, the video camera was placed at an obscure place, a little distance away from the pavement. The time period for which the data were selected was such that sufficient data were available for plotting the speed-flow curve. The data was collected from 6 a.m. to 6 p.m. under widely varying traffic flow conditions.

In order to extract the data required for the analysis, the recorded videos were then transferred to the computer. A Traffic Enumeration Software was used as shown in Fig.1. In the template the number of vehicles passing the entry point between a specified time intervals is calculated. It is the 5 minute time interval that has been considered in this study, so that sufficient data points are available. The speed was calculated, in $\mathrm{km} / \mathrm{h}$, as the ratio of distance and time, where the distance is the trap length and time is the time taken to cross the section.

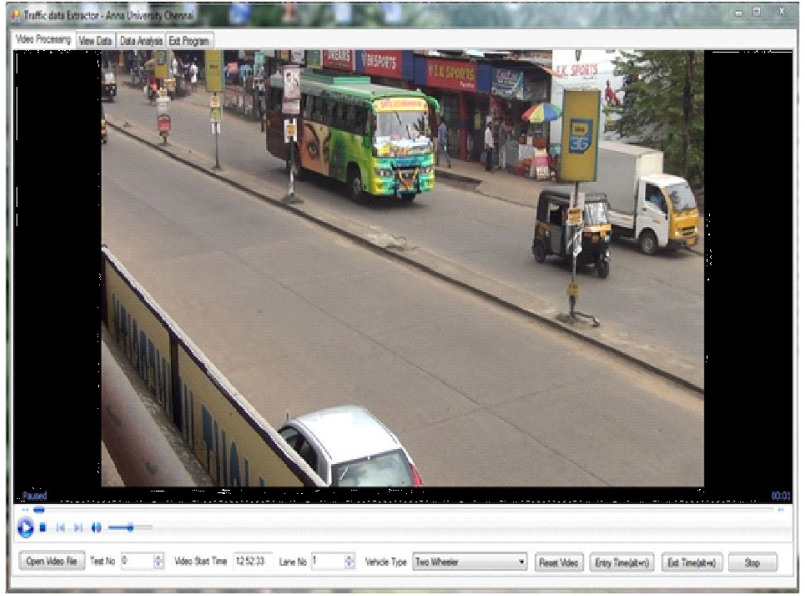

Fig.1: Traffic Enumeration Software

\section{SPACE - OCCUPANCY}

Corresponding to each vehicle type a number of sets of speed and volume data were obtained. The data for each category of vehicle was divided into various groups based on speed ranges (0-5 $\mathrm{km} / \mathrm{h}, 5-10 \mathrm{~km} / \mathrm{h}, 10-15 \mathrm{~km} / \mathrm{h}, 15-20 \mathrm{~km} / \mathrm{h}, 20-25$ $\mathrm{km} / \mathrm{h}, 25-30 \mathrm{~km} / \mathrm{h}, 30-35 \mathrm{~km} / \mathrm{h},>35 \mathrm{~km} / \mathrm{h}$ ). Corresponding to each speed range the flow range was also determined from the speed-flow data available, so that even if the speed data is not available the PCU values can be adopted based on the flow values. Here the flow is taken in veh/ h. In each group a minimum number of data sets were required. The required sample size was calculated by using the formula:

$$
\mathrm{n}=\frac{Z_{a}^{2} \sigma^{2}}{e^{2}}
$$

where, $\mathrm{n}$ - required sample size, $\mathrm{Z}_{\mathrm{a}}=1.96$ at 95\% confidence interval and e - allowable error $=2 \mathrm{~km} / \mathrm{h}$

Table- 2 and 3 gives the required sample size and the available sample size for the various categories of vehicles under consideration. 
Table-2: Required sample size and available sample size of auto, two wheeler, car and bus in each speed range

\begin{tabular}{|c|c|c|c|c|c|c|c|c|}
\hline \multirow[b]{2}{*}{ 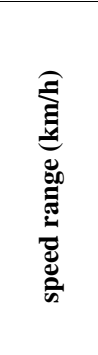 } & \multicolumn{2}{|c|}{ Auto } & \multicolumn{2}{|c|}{$\begin{array}{c}\text { Two } \\
\text { Wheeler }\end{array}$} & \multicolumn{2}{|c|}{ Car } & \multicolumn{2}{|c|}{ Bus } \\
\hline & 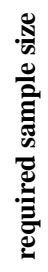 & 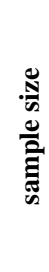 & 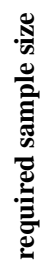 & 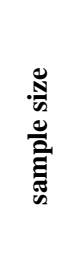 & 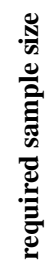 & 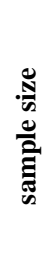 & 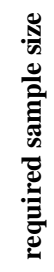 & 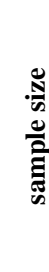 \\
\hline 0 to 5 & 18 & 16 & 12 & 47 & 5 & 5 & NA & $\mathrm{NA}$ \\
\hline 5 to 10 & 36 & 48 & 13 & 250 & 26 & 47 & 10 & 16 \\
\hline 10 to 15 & 19 & 199 & 16 & 608 & 23 & 63 & 30 & 31 \\
\hline 15 to 20 & 21 & 370 & 19 & 647 & 19 & 78 & 20 & 36 \\
\hline 20 to 25 & 26 & 277 & 23 & 396 & 24 & 46 & 11 & 32 \\
\hline 25 to 30 & 22 & 117 & 24 & 110 & 29 & 51 & 25 & 41 \\
\hline 30 to 35 & 28 & 179 & 35 & 44 & 25 & 54 & 22 & 23 \\
\hline
\end{tabular}

Table-3: Required sample size and available sample size of LCV, MCV, HCV and Minibus in each speed range

\begin{tabular}{|c|c|c|c|c|c|c|c|c|}
\hline \multirow[b]{2}{*}{$\begin{array}{l}\text { speed } \\
\text { range } \\
(\mathbf{k m} / \mathbf{h})\end{array}$} & \multicolumn{2}{|c|}{ LCV } & \multicolumn{2}{|c|}{ MCV } & \multicolumn{2}{|c|}{ HCV } & \multicolumn{2}{|c|}{ Minibus } \\
\hline & 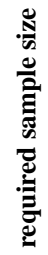 & 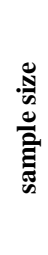 & 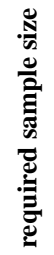 & 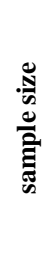 & 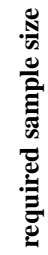 & 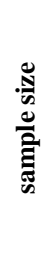 & 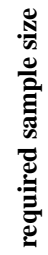 & 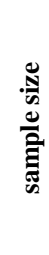 \\
\hline 0 to 5 & NA & NA & NA & NA & NA & NA & NA & NA \\
\hline 5 to 10 & 18 & 27 & 2 & 2 & $\mathrm{NA}$ & NA & 8 & 2 \\
\hline 10 to 15 & 25 & 97 & 3 & 5 & NA & NA & 15 & 12 \\
\hline 15 to 20 & 27 & 123 & 2 & 5 & 3 & 4 & 22 & 16 \\
\hline 20 to 25 & 28 & 66 & 3 & 3 & 1 & 1 & 17 & 17 \\
\hline 25 to 30 & 21 & 30 & 4 & 4 & 1 & 1 & 24 & 3 \\
\hline 30 to 35 & 25 & 30 & NA & NA & NA & NA & NA & NA \\
\hline
\end{tabular}

The cumulative curve of headways was drawn. The $50^{\text {th }}, 85^{\text {th }}$ and $98^{\text {th }}$ percentile headways were found out. The PCU values were determined corresponding to each of these headway values. Using these PCU values, flow was calculated and a non-linear relationship (cubic) between speed and flow was obtained. The one using $50^{\text {th }}$ percentile headway was giving the best $\mathrm{R}^{2}$ value. Thus $50^{\text {th }}$ percentile headway was used for PCU calculation. Table- 4 given below shows the dimensions of the vehicles that were considered for space occupancy.

Table-4: Dimensions of the vehicles considered

\begin{tabular}{|c|c|}
\hline Vehicle Type & Length $\times$ Breadth \\
\hline Auto & $3 \mathrm{~m} \times 1.2 \mathrm{~m}$ \\
\hline Car & $4.5 \mathrm{~m} \times 1.7 \mathrm{~m}$ \\
\hline Two wheeler & $2.1 \mathrm{~m} \times 0.77 \mathrm{~m}$ \\
Bus & $12 \mathrm{~m} \times 2.6 \mathrm{~m}$ \\
LCV & $4.9 \mathrm{~m} \times 1.7 \mathrm{~m}$ \\
MCV & $10 \mathrm{~m} \times 3 \mathrm{~m}$ \\
HCV & $12 \mathrm{~m} \times 3 \mathrm{~m}$ \\
\hline Minibus & $6 \mathrm{~m} \times 2.3 \mathrm{~m}$ \\
\hline
\end{tabular}

The space headway or the longitudinal clearance obtained for each category of vehicle for a particular speed range was added to the length of the vehicle to get the effective length of the vehicle. 1.1 times the width of the vehicle is taken as the effective width of the vehicle. The effective width multiplied by the effective length gives the effective size or the space occupancy of the vehicle. Table 5 and 6 given below shows the calculation for space occupancy.

The length of auto i.e. $3 \mathrm{~m}$ was added along with the average headway in order to get the mean length of auto. The width is calculated as 1.1 times of 1.2 to get $1.32 \mathrm{~m}$. Effective area is obtained as the product of mean length and width. Similarly for car also the values were obtained.

Table-5: Calculation for space occupancy for auto

\begin{tabular}{|c|c|c|c|c|}
\hline $\begin{array}{c}\text { Speed } \\
\text { range } \\
\text { (km/h) }\end{array}$ & $\begin{array}{c}\text { Average } \\
\text { headway } \\
\text { (m) }\end{array}$ & $\begin{array}{c}\text { Mean } \\
\text { length } \\
\text { (m) }\end{array}$ & $\begin{array}{c}\text { Width } \\
(\mathbf{m})\end{array}$ & $\begin{array}{c}\text { Effective } \\
\text { area } \\
\left(\mathbf{m}^{\mathbf{2}}\right)\end{array}$ \\
\hline 0 to 5 & 7.45 & 10.45 & 1.32 & 13.79 \\
\hline 5 to 10 & 5.60 & 8.60 & 1.32 & 11.35 \\
\hline 10 to 15 & 6.61 & 9.61 & 1.32 & 12.69 \\
\hline 15 to 20 & 7.74 & 10.74 & 1.32 & 14.17 \\
\hline 20 to 25 & 8.68 & 11.68 & 1.32 & 15.42 \\
\hline 25 to 30 & 6.57 & 9.57 & 1.32 & 12.63 \\
\hline 30 to 35 & 4.41 & 7.41 & 1.32 & 9.78 \\
\hline
\end{tabular}


Table-6: Calculation for space occupancy for car

\begin{tabular}{|c|c|c|c|c|}
\hline $\begin{array}{c}\text { Speed } \\
\text { range } \\
(\mathbf{k m} / \mathbf{h})\end{array}$ & $\begin{array}{c}\text { Average } \\
\text { headway } \\
\text { (m) }\end{array}$ & $\begin{array}{l}\text { Mean } \\
\text { length } \\
(\mathrm{m})\end{array}$ & $\begin{array}{c}\text { Width } \\
\text { (m) }\end{array}$ & $\begin{array}{c}\text { Effective } \\
\text { area } \\
\left(\mathbf{m}^{2}\right)\end{array}$ \\
\hline 0 to 5 & 10.38 & 14.88 & 1.87 & 27.82 \\
\hline 5 to 10 & 7.49 & 11.99 & 1.87 & 22.43 \\
\hline 10 to 15 & 8.22 & 12.72 & 1.87 & 23.78 \\
\hline 15 to 20 & 8.88 & 13.38 & 1.87 & 25.01 \\
\hline 20 to 25 & 9.68 & 14.18 & 1.87 & 26.52 \\
\hline 25 to 30 & 7.10 & 11.60 & 1.87 & 21.69 \\
\hline 30 to 35 & 4.16 & 8.66 & 1.87 & 16.20 \\
\hline
\end{tabular}

\section{PCU CALCULATiON}

The Passenger Car Unit (PCU) is the ratio of speed ratio of standard vehicle to the $\mathrm{i}^{\text {th }}$ vehicle to the space occupancy ratio of standard vehicle to the $i^{\text {th }}$ vehicle.

$$
\mathrm{PCU}=\frac{\text { Speed ratio of standard vehicle to the } i^{\text {th }} \text { vehicle }}{\text { Space occupancy ratio of standard vehicle to the } i^{\text {th }} \text { vehicle }}
$$

For a particular speed range, the numerator will be unity, then the equation of PCU values will be:

$$
\mathrm{PCU}=\frac{\text { space occupancy of } i^{\text {th }} \text { ve hicle }}{\text { space occupancy of standard vehicle }}
$$

Where, the standard vehicle is taken as car. The PCU calculation for auto is given in Table- 7.

Table-7 : PCU calculation for auto

\begin{tabular}{|c|c|c|c|}
\hline $\begin{array}{c}\text { Speed } \\
\text { Range } \\
\text { (km/h) }\end{array}$ & $\begin{array}{c}\text { Effective } \\
\text { area of } \\
\text { auto }\end{array}$ & $\begin{array}{c}\text { Effective } \\
\text { area of } \\
\text { car }\end{array}$ & PCU \\
\hline 0 to 5 & 13.79 & 27.82 & 0.50 \\
\hline 5 to 10 & 11.35 & 22.43 & 0.51 \\
\hline 10 to 15 & 12.69 & 23.78 & 0.53 \\
\hline 15 to 20 & 14.17 & 25.01 & 0.57 \\
\hline 20 to 25 & 15.42 & 26.52 & 0.58 \\
\hline 25 to 30 & 12.63 & 21.69 & 0.58 \\
\hline 30 to 35 & 9.78 & 16.20 & 0.60 \\
\hline
\end{tabular}

The dynamic PCU values obtained are given in Table 8. Combining the speed and flow data of two locations speed-flow curve was plotted. A wide range of flow values was there corresponding to each speed value so a parabola was drawn enveloping the data points as shown in Fig.2. From this plot, for 
each speed the maximum flow values observed was taken and that was used to find the flow range. It can be seen that below the speed of $20 \mathrm{~km} / \mathrm{h}$ it is congested condition and above that speed it represents free flow condition.

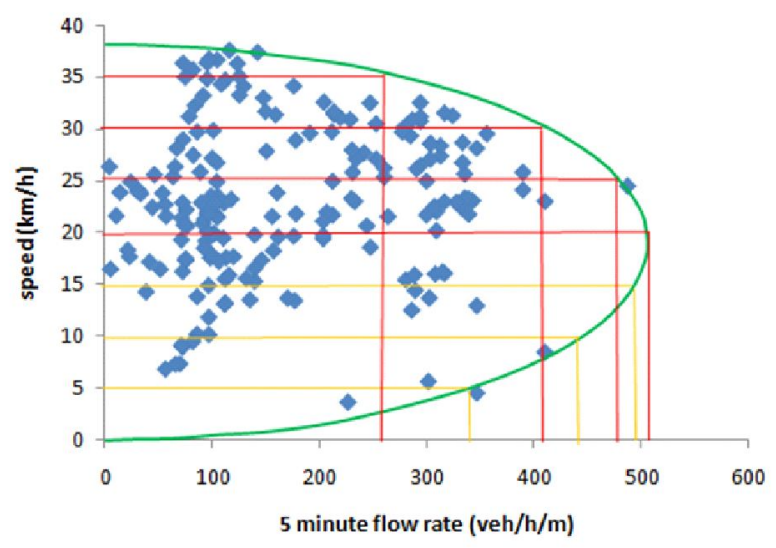

Fig.2: Speed-Flow curve used to find the flow ranges

Table-8: Dynamic PCU values

\begin{tabular}{|l|l|l|l|l|l|l|l|l|l|l|}
\hline $\begin{array}{c}\text { Speed } \\
\text { Ranges } \\
\text { (km/h) }\end{array}$ & $\begin{array}{c}\text { Flow } \\
\text { range } \\
\text { (veh/h/m) }\end{array}$ & $\begin{array}{c}\text { Traffic } \\
\text { condition }\end{array}$ & AR & $\begin{array}{c}\text { Ca } \\
\mathbf{r}\end{array}$ & TW & Bus & LCV & MCV & HCV & Minibus \\
\hline 0 to 5 & 0 to 350 & Congested & 0.50 & 1 & 0.24 & 1.73 & 0.86 & 1.80 & 2.13 & 1.10 \\
\hline 5 to 10 & 350 to 455 & Congested & 0.51 & 1 & 0.24 & 1.73 & 0.86 & 1.80 & 2.13 & 1.11 \\
\hline 10 to 15 & 455 to 500 & Congested & 0.53 & 1 & 0.25 & 2.11 & 0.87 & 1.90 & 2.13 & 1.26 \\
\hline 15 to 20 & 500 to 510 & Congested & 0.57 & 1 & 0.25 & 2.12 & 0.90 & 1.98 & 2.13 & 1.33 \\
\hline 20 to 25 & 485 to 500 & Free flow & 0.58 & 1 & 0.27 & 2.27 & 0.93 & 2.05 & 2.38 & 1.40 \\
\hline 25 to 30 & 410 to 485 & Free flow & 0.58 & 1 & 0.29 & 2.27 & 0.96 & 2.17 & 4.40 & 1.41 \\
\hline 30 to 35 & 275 to 410 & Free flow & 0.60 & 1 & 0.30 & 2.44 & 1.02 & 2.17 & 4.40 & 1.41 \\
\hline$>35$ & 0 to 275 & Free flow & 0.60 & 1 & 0.30 & 2.44 & 1.02 & 2.17 & 4.40 & 1.41 \\
\hline
\end{tabular}

\section{RELIABILITY OF DYNAMIC PCU VALUES}

It should be proved that the dynamic PCU values obtained in this study could be used for further studies. For that the density is being found out from the available speed-flow data using the traffic stream model:

$$
\mathrm{q}=\mathrm{ku}
$$

where, $\mathrm{q}$ - flow, $\mathrm{k}$ - density and $\mathrm{u}$-speed

Three sets of density values were found out using flow in veh/h, flow in $\mathrm{pcu} / \mathrm{h}$ using IRC PCU values and flow in pcu/h using dynamic PCU values. From Table-9 and 10, it is infer that the obtained dynamic PCU values proved to be logical based on the $\mathrm{R}^{2}$ values obtained and also gave a better fit for speeddensity relationship. 
Table-9: Relationship between speed and density for TRUNK Road (Direction 1)

\begin{tabular}{|l|c|c|}
\hline Density in & Relationship & $\mathbf{R}^{2}$ \\
\hline veh/h & $\mathrm{y}=-0.096 \mathrm{x}+34.25$ & 0.737 \\
\hline pcu/h (using IRC PCU values) & $\mathrm{y}=-0.090 \mathrm{x}+33.22$ & 0.752 \\
\hline pcu/h (using dynamic PCU values) & $\mathrm{y}=-0.134 \mathrm{x}+33.54$ & 0.755 \\
\hline
\end{tabular}

Table-10: Relationship between speed and density for TRUNK Road (Direction 2)

\begin{tabular}{|l|c|c|}
\hline Density in & Relationship & $\mathbf{R}^{2}$ \\
\hline veh/h & $\mathrm{y}=-0.023 \mathrm{x}+18.49$ & 0.467 \\
\hline $\mathrm{pcu} / \mathrm{h}$ (using IRC PCU values) & $\mathrm{y}=-0.026 \mathrm{x}+18.28$ & 0.538 \\
\hline pcu/h (using dynamic PCU values) & $\mathrm{y}=-0.042 \mathrm{x}+18.27$ & 0.544 \\
\hline
\end{tabular}

\section{SUMMARY AND CONCLUSION}

Two mid-block sections in Ongole city were selected as the study sections. Video graphic technique was used for the traffic flow data collection. The geometric data were collected manually from the field. A Traffic Enumeration Software was used for extracting speed, flow and headway data. Space occupancy method was used for PCU determination where in the space headway of each vehicle was also taken into consideration along with the projected area of the vehicle.

Dynamic PCU values were found out corresponding to both speed and flow ranges. Since most of the vehicles were moving within the speed range of 0 to $35 \mathrm{~km} / \mathrm{h}$, dynamic PCU values were found out only in these ranges. For speeds greater than $35 \mathrm{~km} / \mathrm{h}$, the maximum PCU values obtained can be used. Density values were found out for each mid-block sections and the speed-density curve was plotted for three sets of density values : in veh/km, $\mathrm{pcu} / \mathrm{h}$ (using both IRC and dynamic PCU values), the best fit linear equation was observed for the curve plotted with flow obtained using dynamic PCU values. The estimated dynamic PCU values proved to be logical and also gave a better fit for speed-density relationship.

\section{REFERENCES}

[1] Kumar, P., Arkatkar, S.S. and Joshi, G. (2018). "New Approach for Estimating Passenger Car Units on Multilane Urban Roads with Heterogeneous Traffic Conditions", Journal of Transportation Engineering, Part A: Systems, 144 (3), 1-24.

[2] Kumar, P., Arkatkar, S.S., Joshi, G. and Dhamaniya, A. (2017). "New methodology for estimating PCU on multi-lane urban roads under mixed traffic scenario based on area occupancy", Transportation Research Board 96th Annual Meeting. Washington, DC: Transportation Research Board, National Research Council.

[3] Mallikarjuna, C. and Rao, K.R. (2006). "Modeling of passenger car equivalency under heterogeneous traffic conditions", 22 $2^{\text {nd }}$ Australian Road Research Board Conf. Canberra, Vol. 7, Australia: Australian Road Research Board.

[4] Mishra et al., (2017). "Novel Area OccupancyBased Method for Passenger Car Unit Estimation on Multilane Urban Roads Under Heterogeneous Traffic Scenario", Transportation Research Record, Journal of the Transportation Research Board, 2615(1):82-94.

[5] Paul, P. K. and Sarkar. P.K. (2013). "Determination of dynamic PCUs of different types of passenger vehicles on urban roads: A case study, Delhi urban area”, Indian Highways, 41 (4): 37- 47.

[6] Preethi, P. and Ashalatha, R. (2016). "Estimation of Dynamic PCU Using the Area Occupancy Concept at Signalised Intersections", International Conference on Transportation and Development, 2016, 825-837.

[7] Pooja, R., Shahana, A., Gowri, A. and Ravi Shankar, A.U. (2018). “An approach for estimation of 
passenger car unit values of vehicles based on influence of neighboring vehicles", Proc., 97 $7^{\text {th }}$ Transportation Research Board Annual Meeting. Washington, DC: Transportation Research Board, National Research Council.

[8] Pooja, R., Kalaanidhi, S., Gowri, A. and Ravi Shankar, A.U. (2019). "Review of Methods for Estimation of Passenger Car Unit Values of Vehicles”, J. Transp. Eng., Part A: Systems, 145(6), 04019019.
[9] Srikanth, S. and Mehar, A. (2017). "A modified approach for estimation of passenger car units of different vehicle types on intercity multilane highways", Archives of transport, 42(2), 65-74.

[10] Swamy, C. A. R., Munigety, C.R. and Anjaneyulu, M.V.L.R. (2016). "Passenger car unit based on influence area", In Proc., 12th Transportation Planning and Implementation Methodologies for Developing Countries. Maharashtra, India: IIT Bombay. 